\title{
Modelling aboveground forest biomass using airborne laser scanner data in the miombo woodlands of Tanzania
}

\author{
Ernest William Mauya ${ }^{*}$, Liviu Theodor Ene ${ }^{1}$, Ole Martin Bollandsås ${ }^{1}$, Terje Gobakken ${ }^{1}$, Erik Næsset ${ }^{1}$, \\ Rogers Ernest Malimbwi and Eliakimu Zahabu²
}

\begin{abstract}
Background: Airborne laser scanning (ALS) has emerged as one of the most promising remote sensing technologies for estimating aboveground biomass (AGB) in forests. Use of ALS data in area-based forest inventories relies on the development of statistical models that relate AGB and metrics derived from ALS. Such models are firstly calibrated on a sample of corresponding field- and ALS observations, and then used to predict AGB over the entire area covered by ALS data. Several statistical methods, both parametric and non-parametric, have been applied in ALS-based forest inventories, but studies that compare different methods in tropical forests in particular are few in number and less frequent than studies reported in temperate and boreal forests. We compared parametric and non-parametric methods, specifically linear mixed effects model (LMM) and $k$-nearest neighbor ( $k$-NN).
\end{abstract}

Results: The results showed that the prediction accuracy obtained when using LMM was slightly better than when using the $k$-NN approach. Relative root mean square errors from the cross validation was $46.8 \%$ for the LMM and $58.1 \%$ for the $k$-NN. Post-stratification according to vegetation types improved the prediction accuracy of LMM more as compared to post-stratification by using land use types.

Conclusion: Although there were differences in prediction accuracy between the two methods, their accuracies indicated that both of methods have potentials to be used for estimation of AGB using ALS data in the miombo woodlands. Future studies on effects of field plot size and the errors due to allometric models on the prediction accuracy are recommended.

Keywords: Parametric models, Prediction accuracy, Non-parametric models, LMM, k-NN, Sampling design

\section{Background}

Estimation of aboveground biomass (AGB) in tropical forests is important for generating information needed for sustainable forest management and understanding the contribution of tropical forests in the global carbon cycle. Particularly in the latter context, estimates of AGB are needed as a primary variable for establishing the increments or decrements in carbon stored in tropical forests, which is typically converted from AGB by using a factor of $50 \%$ or less [1]. In the recent decade, reducing

\footnotetext{
*Correspondence: ernest.mauya@nmbu.no; ernestmauya@gmail.com 1 Department of Ecology and Natural Resource Management, Norwegian University of Life Sciences, P.O. Box 5003, 1432 Ås, Norway

Full list of author information is available at the end of the article
}

emissions from deforestation and degradation (REDD+), a program under United Nations Framework Conventions on Climate change, has motivated large-scale forest carbon inventories in tropical forests. REDD+ aims to provide positive incentives for developing countries to initiate activities related to reducing carbon emissions, sustainable forest management, and enhancement of forest carbon stock [2]. Unlike other conservation projects, REDD+ is results based, which means that financial benefits rely on forest carbon stock changes that are measured, reported, and verified (MRV). Thus, establishing effective MRV systems that comply with the guidelines of the Intergovernmental Panel on Climate Change, is 
considered as an integral part of REDD+ implementation [3].

In Tanzania, the National Forestry Resources Monitoring and Assessment (NAFORMA), which is the national forest inventory of Tanzania, has established a total of 30,773 field plots distributed across mainland Tanzania [4]. NAFORMA is expected to be used to produce AGB data for the national forest carbon MRV system necessary for the implementation of REDD+ activities in Tanzania $[5,6]$. However, being a field-based inventory, estimates of parameters related to AGB and AGB changes derived from NAFORMA data are not expected to be sufficiently precise to meet the accuracy requirements for a REDD+ MRV system. Therefore, the use of remotely sensed data as auxiliary information is considered as an option towards developing a cost-efficient MRV system in the country.

Airborne laser scanning (ALS) has recently received much scientific and operational attention for estimating AGB than any of the other remote sensing techniques [7]. The potential of ALS has previously been reported in the Nordic countries where it has been used operationally for management inventories for almost 15 years [8]. Recently, promising results from tropical forests [e.g. 9, 10] have also been reported, which have increased the interest in using ALS for REDD+ MRV purposes.

However, large scale AGB assessments with ALS remain challenging due to logistics, cost and the data volume involved if wall-to-wall coverage is to be applied [11]. For such situations, a systematic sampling approach using ALS as a strip sampling tool is a viable option [12]. Within this approach, a collection of ALS measurements are taken along individual flight lines that cover only a small portion of the area of interest. The flight lines are aligned with a network of ground plots [12] which allow the development of statistical models relating the ground reference AGB to metrics derived from coincident ALS data. These models are then used to predict AGB over the entire area covered by ALS strips, and subsequently these predictions are used for final estimation of AGB for the area of interest using either design-based model-assisted or modeldependent inferential frameworks [e.g. 13, 14]. Thus, the quality of the AGB estimates produced by ALSbased inventories relies heavily on the development and application of predictive AGB models.

A review study by Fassnacht et al. [15] shows that the most common prediction methods in ALS-based forest inventories are ordinary least square regression, support vector machines, nearest neighbor-based methods (i.e. $k$-NN and $k$-MSN), and random forest. Of all the methods, ordinary least square regression with stepwise variable selection has been most frequently used for building models between field measurements and ALS metrics [16]. The main advantage of using this type of methodology is the simplicity and clarity of the resulting models [17], especially when the relationship between AGB and the ALS metrics is almost linear. However, fitting and applicability of ordinary least square regression models relies on a number of basic assumptions in relation to the residual distribution which are: independence, normality and constant variance [18]. These assumptions are barely taken into account in most studies [19], especially when dealing with the data that are collected from complex field survey designs that involve clustered observations, repeated measurements, longitudinal measurements, and blocked data. Ignoring the model assumptions when fitting ordinary least square regression models, might lead to spatially correlated errors and consequently, invalid significance tests [20].

Linear mixed effects models (LMMs) offer a modeling and prediction method that is very effective on clustered or spatially correlated data [21, 22]. In addition to accounting for covariates through fixed parameters as in ordinary least square regressions, mixed effects models can also account for various sources of heterogeneity and randomness in the data caused by known and unknown factors by means of random parameters. Application of LMMs are however limited in ALS-based inventories as compared to other prediction methods [23].

Non-parametric approaches, such as $k$-nearest neighbor $(k-\mathrm{NN})$ are also considered as an alternative to ordinary least regression, since they do not rely on any distributional assumptions of the data [24]. Thus, $k$-NN is a highly relevant alternative to deal with non-linear and possibly diverse relationships between independent and dependent variables. Furthermore, like other nearest neighbor techniques, $k-\mathrm{NN}$ allows for both univariate and multivariate predictions of continuous and categorical variables $[25,26]$. In forest inventory applications, $k$-NN approaches have been frequently applied in model-dependent frameworks with good results [27] and have also been used for mapping of various forest attributes [28, 29]. Several studies [e.g. 30-32] have compared the performance of $k$-NN with ordinary least square regression (OLS) models in temperate and boreal forests, but few studies have compared LMMs with $k$-NN, especially in the context of the ALS-based inventory. Of particular interest is application and validation of such techniques in the tropical dry forests of Africa, where the application of statistical methods commonly used in ALS-based forest inventories are still limited compared with temperate and boreal forests. Given the growing potential of the use of national forest 
inventory data and ALS auxiliary information for supporting REDD+ activities in tropical forests [e.g. 6, 33], it is important to explore modeling methods that fully utilize the attributes of design as a fundamental step towards reliable and accurate estimation of AGB using ALS.

Irrespective of the method used, stratification and post-stratification have been considered as effective tools for improving precision of estimates in ALS-based inventories [34]. Stratification according to forest age and/or site quality is commonly used in boreal forests [e.g. 35, 36]. In highly heterogeneous tropical forests, stratification/post-stratification based on vegetation types have been considered as a viable and practical option [37]. However, due to practical limitations, few studies have attempted to assess the effects of stratification and post-stratification on the prediction accuracy and thus on final estimates in tropical forests. For example, in most of the previous studies only a limited number of field plots were available for AGB modeling due to issues such as accessibility and cost. Thus, stratification or post-stratification of the study areas has not been regarded as viable since it could lead to even smaller sample sizes per stratum, making it difficult to fit reliable statistical models for each class [38]. In such situations, most of the previous studies opted to combine sample plot data across classes, for example vegetation types, thus ignoring the effect of vegetation types and associated information.

Our study was conducted in the tropical forests of southern Tanzania which is mainly dominated by the miombo woodlands, along with some forest, cultivated land, and other vegetation types. Miombo woodlands occupy a substantial area of forest land in Tanzania (92 \%) [4] and extend to six other countries in sub-Saharan Africa, including Angola, Zimbabwe, Zambia, Malawi, Mozambique, and Democratic Republic of Congo [39]. From a global perspective, miombo woodlands have received considerable attention in the last decade because of its potential to act as a reservoir of belowground and aboveground carbon stocks [40]. Biodiversity is also significant in the miombo woodlands with an estimate of 8500 species of higher plants and more than half of them are endemic [39]. Application of ALS in such areas represents the typical challenge that would be expected when using ALS data for modelling AGB in tropical forests with a high number of species, and diverse vegetation and land use types. The main objective of our study was to assess the performance of parametric and non-parametric methods for modeling and prediction of AGB using ALS data. As a secondary objective, we also assessed the effects of post-stratification by vegetation and land use types on the prediction accuracy of the parametric models.

\section{Results}

\section{Performance of the parametric and non-parametric methods}

The OLS model with square root transformed response variable was selected for building up LMMs. The model contained eight explanatory variables consisting of both height percentiles and canopy density metrics selected using the best subset procedure. The OLS model showed cluster effects on the residual distributions as illustrated in Fig. 1. Some clusters displayed residuals that were above, and some below the zero line, indicating that cluster effects should be accounted for in the modelling. Comparison of the OLS model (Model 1) and the LMM (Model 2) using likelihood ratio test suggested a statistically significance difference $(p<0.001)$ between the two models. Model 2 was considered to have better fit with smaller value of AIC as compared to Model 1.

Re-fitting Model 2 with different correlation structures (i.e., spatial autocorrelation functions and compound symmetry correlation structures) did not significantly improve model fit. The AIC values did not improve when compared to the values in the model without the autocorrelation functions (i.e., Model 2). Furthermore, the likelihood ratio test indicated that there was no statistical significance difference between the models with and without correlation structure $(p>0.05)$. This may also indicate that there is no spatial autocorrelation of the residuals within the clusters. Modelling the residual variance at the cluster level by using variance function (varIdent) improved the model performance as measured by the AIC. The likelihood ratio test indicated a statistically significant difference $(p<0.0001)$ between Model 2 and Model 3. The standard errors of the parameters for Model 3 were smaller compared to the other models (Table 1). The quality of Model 3 was further analyzed by comparing an intercept model of Model 3 residuals and a similar model with a random intercept by means of the likelihood ratio test. The test indicated that the two models were not statistically significantly different from each other $(p>0.05)$, implying that Model 3 has successfully accounted for the dependency and heteroscedasticity in the data, therefore the residuals can be considered as independent.

The $k$-NN imputation tested with different values of $k$ ranging from 1 to 10 , have shown that, $k=10$ was the optimal choice with relatively smaller $\mathrm{RMSE}_{\mathrm{CV}} \%$ value. We further tested the dependency and heteroscedasticity of the residuals obtained from best $k$-NN imputation 


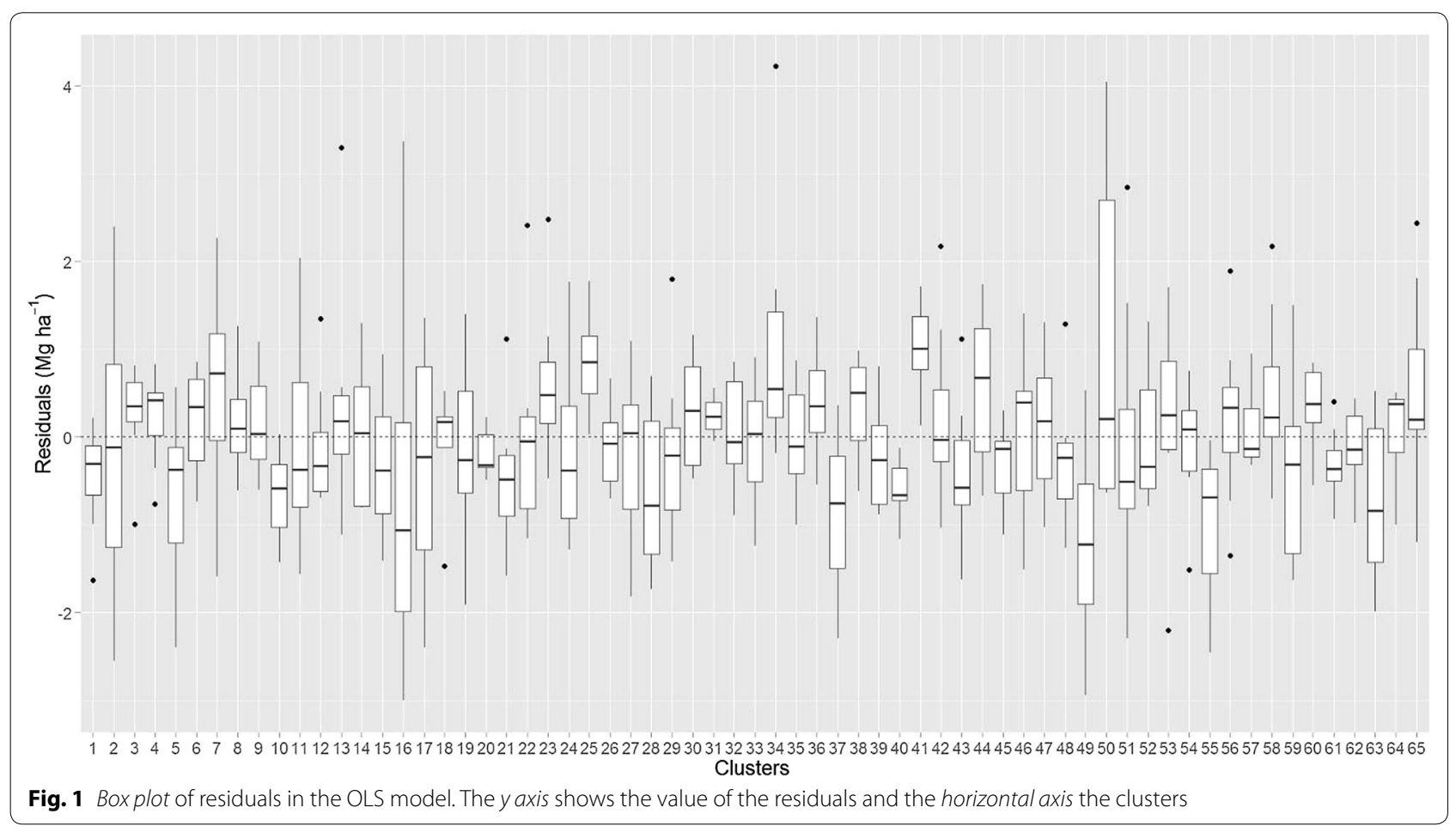

Table 1 Parameter estimates and standard errors of the tested models

\begin{tabular}{|c|c|c|c|c|c|c|}
\hline \multirow[t]{2}{*}{ Covariate $^{a}$} & \multicolumn{2}{|l|}{ Model 1} & \multicolumn{2}{|l|}{ Model 2} & \multicolumn{2}{|l|}{ Model 3} \\
\hline & Estimate & Standard error & Estimate & Standard error & Estimate & Standard error \\
\hline Intercept & 0.8630 & 0.2520 & 0.7385 & 0.2848 & 0.6702 & 0.2238 \\
\hline PF70 & 0.3481 & 0.0338 & 0.3515 & 0.0345 & 0.3701 & 0.0273 \\
\hline TF0 & 3.7779 & 0.5713 & 3.8436 & 0.6003 & 4.4363 & 0.4829 \\
\hline TF5 & 4.0742 & 1.2839 & 3.7574 & 1.2964 & 1.7055 & 1.0384 \\
\hline TF8 & -6.2178 & 1.9462 & -6.5277 & 1.9310 & -4.1964 & 1.4833 \\
\hline PL20 & 0.3191 & 0.1241 & 0.2684 & 0.1232 & 0.1844 & 0.1100 \\
\hline PL30 & -0.2295 & 0.1110 & -0.1845 & 0.1096 & -0.1059 & 0.0951 \\
\hline TL7 & -12.4990 & 4.0241 & -11.9814 & 4.0086 & -6.8397 & 2.7174 \\
\hline TL8 & 18.3840 & 5.5361 & 19.5302 & 5.4729 & 10.8928 & 3.7172 \\
\hline
\end{tabular}

a PF70 = Percentile of the first echo canopy heights for $70 \%(\mathrm{~m}) ; \mathrm{PL} 20$ and PL30 = Percentiles of the last echo canopy heights for 20 and $30 \%$ (m); TF0, TF5, and TF8 = Canopy densities corresponding to the proportion of first echoes above fraction \#0 (1.3 m), \#5, and \#8 (see text); TL7 and TL8 = Canopy densities corresponding to the proportion of last echoes above fraction \#7 and \#8 (see text)

(i.e., $\mathrm{k}=10$ ), by comparing two residual models using the likelihood ratio test (i.e., a residual intercept model and a random intercept model). The results from the likelihood ratio test showed that there was no statistically significant differences between the two models. Comparing the results of the best parametric model (i.e., Model 3) and the non-parametric (i.e., $k=10$ ) (Table 2), our results suggest that the parametric models performed well in our dataset as indicated by both $\mathrm{R}^{2}$ and $\mathrm{RMSE}_{\mathrm{CV}} \%$. Graphical illustrations for the performances of the two methods are presented in Fig. 2.

\section{Effect of post-stratification on prediction accuracy of the parametric models}

To account for the effect of post-stratification on model accuracy, we assessed the performance of the parametric model (i.e., Model 3) on different vegetation and land use types (Table 3 ). The results indicated that there were variations in the prediction accuracy of the model across the categories. The RMSE \% and $\mathrm{RMSE}_{\mathrm{CV}} \%$ of Model 3 (i.e., non-post-stratified model) varied from one category to another; smaller values of RMSE \% and $\mathrm{RMSE}_{\mathrm{CV}} \%$ were reported for vegetation types as compared to land use types. 
Table 2 Predictors, pseudo $R$-squared $\left(\mathbf{R}^{2}\right)$, and relative root mean square error from the cross validation $\left(R_{M S E} \%\right)$ of the two prediction methods

\begin{tabular}{|c|c|c|c|}
\hline Prediction method & Predictors $^{\mathbf{a}}$ & $\mathbf{R}^{2}$ & $\mathrm{RMSE}_{\mathrm{CV}} \%$ \\
\hline LMM (Model 3) & PF70, TF0, TF5, TF8, PL20, PL30, TL7, TL8 & 0.69 & 46.8 \\
\hline$k-N N(k=10)$ & PL80, TF0, TL2, PF80, TL4, TL8, PS40, TL5, TF2, TL7, TL6, PF70, MaxF, PL90, PL50, MeanL, TF7, PF10, PL60, TF3 & 0.58 & 55.9 \\
\hline
\end{tabular}

a PF10, PF70, and PF80 = Percentiles of the first echo canopy heights for $10 \%, 70 \%$, and $80(\mathrm{~m})$; PL20, PL30, PL40, PL50, PL60, and PL90 = Percentiles of the last echo canopy heights for 20, 30, 40, 50, 60, and $90 \%$ (m); TF0, TF2, TF3, TF5, TF7, and TF8 = Canopy densities corresponding to the proportion of first echoes above fraction $\# 0(1.3 \mathrm{~m}), \# 2, \# 3, \# 5, \# 7$, and \#8;TL2, TL4, TL6, TL7, and TL8 = Canopy densities corresponding to the proportion of last echoes above fraction \#2, \#4, \#6, \#7, and \#8; MaxF and MeanL = Maximum and Mean of the canopy height distributions of the first and last echoes, respectively
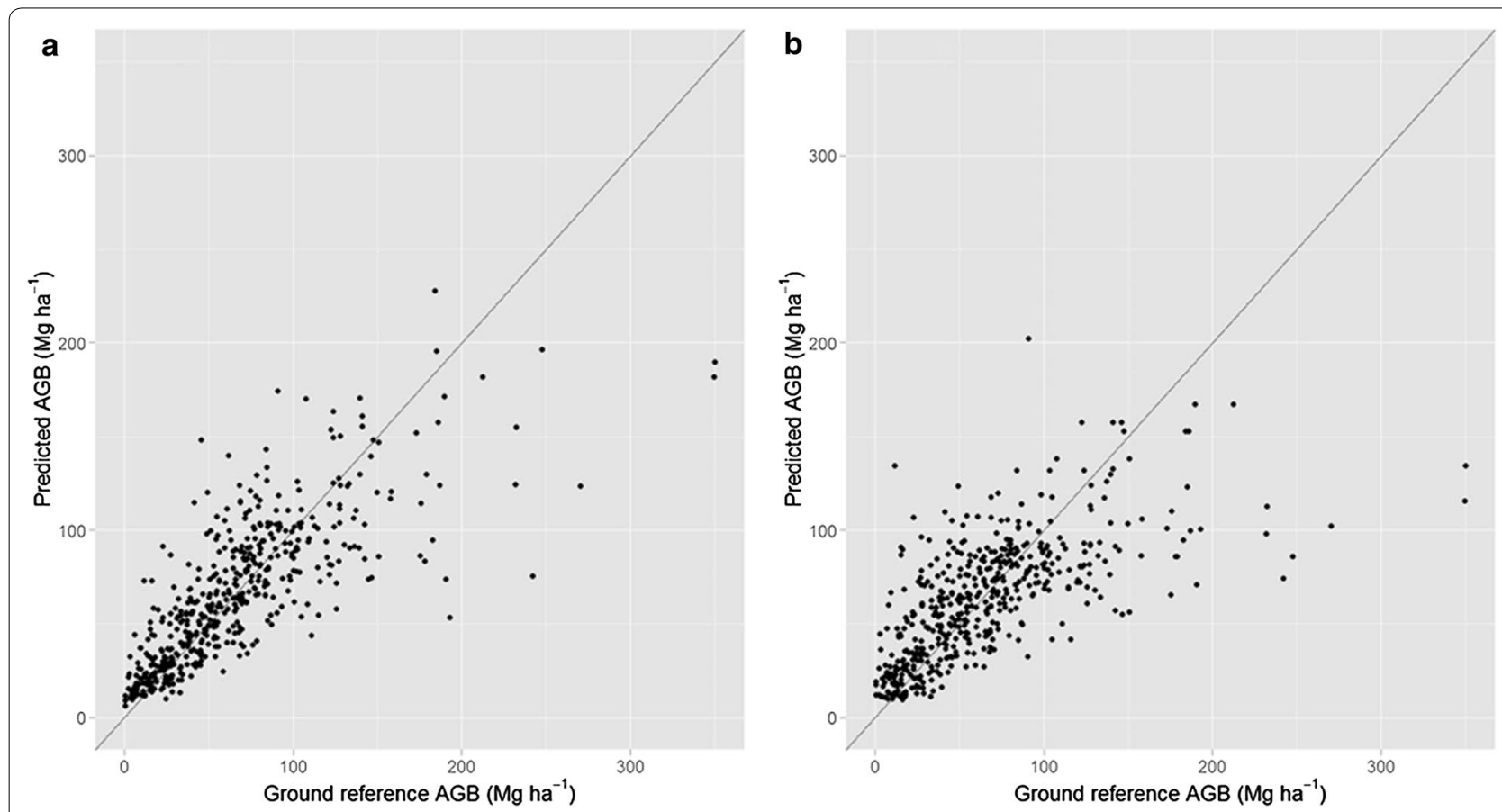

Fig. 2 Relationship between ground reference and predicted AGB for LMM (a) $k-N N(k=10)(\mathbf{b})$

Separate random intercept models were fitted for each of the categories (Table 4) and compared with the nonpost-stratified model presented in the previous section. Generally, the $\mathrm{RMSE}_{\mathrm{CV}}$ \% for the post-strata models were relatively small compared to the values obtained when evaluating the non-post-stratified model across respective post-strata. The accuracy of the post-strata models varied in terms of model fits (i.e., $\mathrm{R}^{2}$ ) and $\mathrm{RMSE}_{\mathrm{CV}} \%$ depending on the vegetation and land use types (Table 4). Graphical plots in Figs. 3 and 4 illustrate the performance of the post-strata models.

\section{Discussion}

Our study aimed at comparing the performance of the parametric (LMMs) and non-parametric $(k-\mathrm{NN})$ methods for predicting AGB using ALS data in the miombo woodlands of Tanzania. Effects of post-stratification by vegetation and land use types on the prediction accuracy of the parametric method were considered as the secondary objective. The findings from this study demonstrate that both LMMs and $k$-NN are suitable methods for predicting AGB using ALS data. To our understanding this is one among the early studies attempting to use ALS in the miombo woodlands of Tanzania. Thus the findings of this study open up methodological insights on the use of ALS as tool for AGB assessment in similar type of vegetation in sub-Saharan Africa.

Specifically, the findings have shown that LMM is the best prediction method; by allowing the specific field sampling design to be accounted for in the modeling, but also by having slightly higher prediction accuracy compared to $k$-NN. This is not surprising, and has been 
Table 3 Performance of the parametric model (Model 3) on different vegetation and land use types

\begin{tabular}{|c|c|c|c|c|}
\hline Category $^{a}$ & RMSE $\left(M g \mathrm{ha}^{-1}\right)$ & $\operatorname{RMSE}_{\mathrm{CV}}\left(\mathrm{Mg} \mathrm{ha}^{-1}\right)$ & RMSE \% & RMSE $_{\mathrm{CV}} \%$ \\
\hline \multicolumn{5}{|l|}{ Vegetation type } \\
\hline Forest & 22.7 & 25.1 & 25.7 & 28.4 \\
\hline Woodlands & 29.4 & 31.6 & 44.3 & 47.7 \\
\hline Other cover types & 37.6 & 38.5 & 80.2 & 82.1 \\
\hline \multicolumn{5}{|l|}{ Land uses type } \\
\hline Production and protection forests & 30.4 & 31.1 & 40.2 & 41.1 \\
\hline Wildlife reserves & 25.5 & 26.3 & 50.2 & 52.0 \\
\hline Agriculture and other land use types & 33.2 & 34.0 & 73.0 & 74.7 \\
\hline
\end{tabular}

${ }^{a}$ Forest = land spanning more than 0.5 ha with trees that have heights of more than $5 \mathrm{~m}$ and a canopy cover of more than $10 \%$. It does not include land that is predominantly under agricultural or urban land use. Woodland = forestland with less dense canopy cover compared to forest. Other cover types = all cover types that were neither forest nor woodlands. Production and protection forests $=$ forest areas designated for protection of water (i.e. catchment forests) and that designated for production of wood, respectively. Wildlife reserves = forest areas designated for game reserves and game controlled areas. Agriculture and other land use types = areas designated primarily for a function other than production, protection or game reserves. Details descriptions of these categories are given in MNRT [60]

Table 4 Predictors, number of observations $(n)$, pseudo $R$-squared $\left(R^{2}\right)$, and relative root mean square error from the LOOCV (RMSE ${ }_{C V} \%$ ) for separate LMM fitted for different vegetation types and land use types

\begin{tabular}{|c|c|c|c|c|}
\hline Category $^{a}$ & Predictors $^{\mathbf{b}}$ & $n$ & $\mathrm{R}^{2}$ & RMSE $_{\mathrm{cv}} \%$ \\
\hline \multicolumn{5}{|l|}{ Vegetation type } \\
\hline Forest & PF20, MaxL, MeanL, PL10, PL40, PL70, PL90, TL9 & 40 & 0.85 & 23.9 \\
\hline Woodlands & PF70, TF0, PL20 & 391 & 0.63 & 45.3 \\
\hline Other cover types & MeanF, PF20, PF60, TF5, MaxL, PL70 & 58 & 0.83 & 68.3 \\
\hline \multicolumn{5}{|l|}{ Land use type } \\
\hline Production and protection forests & PF40, PF60, PF70, TF0, TF9, PL20 & 314 & 0.64 & 40.8 \\
\hline Wildlife reserves & CVF, PF20, PF90, TF5 & 91 & 0.73 & 49.8 \\
\hline Agriculture and other land uses & TF1, TF4, MaxL, MeanL, CVL, TL0, TL4 & 84 & 0.69 & 68.0 \\
\hline
\end{tabular}

${ }^{a}$ Forest $=$ land spanning more than 0.5 ha with trees that have heights of more than $5 \mathrm{~m}$ and a canopy cover of more than $10 \%$. It does not include land that is predominantly under agricultural or urban land use. Woodland = forestland with less dense canopy cover compared to forest. Other cover types = all cover types that were neither forest nor woodlands. Production and protection forests $=$ forest areas designated for protection of water (i.e. catchment forests) and that designated for production of wood, respectively. Wildlife reserves = forest areas designated for game reserves and game controlled areas. Agriculture and other land use types $=$ areas designated primarily for a function other than production, protection or game reserves. Details descriptions of these categories are given in MNRT [60] b PF20, PF40, PF70, and PF90 = Percentiles of the first echo canopy heights for $20 \%, 40 \%, 70 \%$, and 90 (m); PL10, PL20, PL70, and PL90 = Percentiles of the last echo canopy heights for 10, 20,70, and $90 \%$ (m); TF0, TF1, TF4, and TF5 = Canopy densities corresponding to the proportion of first echoes above fraction \#0 (1.3 m), \#1, \#4, and \#5; TL0, TL4, TL6, TL7, and TL8 = Canopy densities corresponding to the proportion of last echoes above fraction \#0 (1.3 m), \#4, \#6, \#7, and \#8; MeanF and MeanL = arithmetic mean of first or last echo laser canopy heights, respectively $(\mathrm{m})$; MaxF and MaxL = maximum of first or last echo laser canopy heights, respectively $(\mathrm{m}) ; \mathrm{CVF}$ and $\mathrm{CVL}=$ Coefficient of variations for the first and last echo laser canopy heights, respectively

reported in most of the studies that have attempted to compare parametric and non-parametric methods in prediction of various forest attributes [e.g. 30, 41, 42]. However, the strength of $k-\mathrm{NN}$ is that it was able to account for the dependence and heteroscedasticity in the data. This indicates that it can reliably be used for estimation and making inference when deemed necessary, especially in the design-based framework of forest inventory [e.g. 43, 44] with non-parametric based estimators (e.g. difference estimator).

Results based on the LMM illustrate that incorporating the cluster structure by using variance function in the model selection process can result in a model with better fit, as supported by the likelihood ratio test. This implies that it is the between-cluster variability that should be considered when calibrating the ALS models using NAFORMA data, rather than the within-cluster variability. By modelling the residual variance per cluster through an appropriate variance structure (i.e., the varIdent structure) we were able to account for this variability in the data, which resulted in a model with smaller standard errors for the parameter estimates as compared to the other tested models (Table 1). Smaller standard errors of the parameter estimates (Table 1) indicate that the model is more efficient when predicting outside the sample. Furthermore, smaller standard errors of the parameter estimate is an important property in improving precision of the estimates, especially when making inference using 

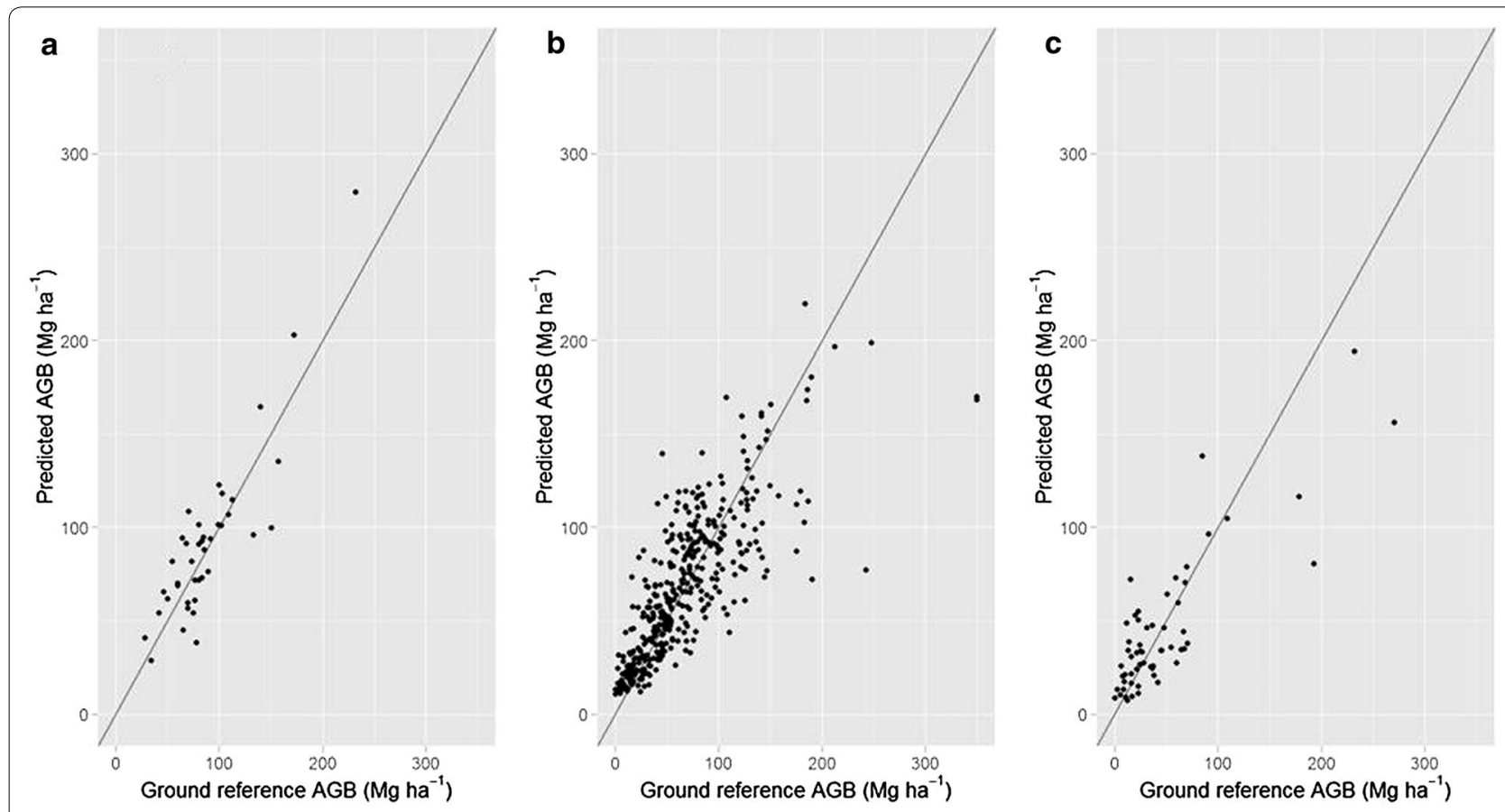

Fig. 3 Relationship between ground reference and predicted AGB for LMM in forest (a) woodlands (b) other cover types (c)


Fig. 4 Relationship between ground reference and predicted AGB for LMM in production and protection forests (a) wildlife reserves (b) agriculture and other land uses (c) 
model-based estimators [45] which theoretically rely on the quality of the model parameters.

Further evaluation of the best non-post-stratified model across post-strata, showed that there were variations in prediction accuracy across different vegetation and land use types. This could likely be attributed to the difference in stem diameter and the number of trees per unit area, which entirely affect the distribution of AGB and the characteristics of the ALS data in each of the post-strata. When fitting separate models by post-strata, our findings showed that that there was a slight gain in prediction accuracy compared to the use of non-poststratified model in the respective post-strata. This might be due to the homogeneity of the respective category, which in turns improves the relationship between ALS metrics and the ground reference AGB. For example, in the post-strata such as forest, or production and protection forests where the distribution of AGB is characterized by trees with high canopy cover and more uniform stems, the RMSE $\mathrm{CV}_{\mathrm{C}} \%$ were relatively smaller compared to other categories. On the other hand, the higher RMSE $_{C V}$ \% value in the agricultural and other land uses might be attributed to the fact that most of the trees in this category are scattered with sparse canopy, and the tree crowns are smaller with some appearing to be in a degraded form.

Although post-strata models performed well compared to non-post-stratified models, their practical application in the miombo woodlands poses a number of challenges when used for estimation and inference. Based on the sampling design described in this study, the use of post-strata models would require having thematic maps for the land use classes and vegetation types. Such maps are not trivial to produce, and our results (not presented) indicated that the classification accuracies vary substantially among these categories. Thus, since the difference between the non-post-stratified model and the poststrata models were modest, we would rather recommend the non-post-stratified model (which disregards the land use and vegetation types) to be more adequate for most applications that will involve large-scale AGB estimation supported by ALS data, at least until high quality thematic maps are made available.

Generally, the finding of our study in terms of model quality criteria such as $\mathrm{R}^{2}$ and $\mathrm{RMSE}_{\mathrm{CV}} \%$ for non-poststratified and post-strata models are in line with most of the published studies from tropical forests [46-49]. The majority of these studies reported $\mathrm{R}^{2}$ ranging from $64 \%$ [50] to $90 \%$ [51]. Similarly, a study by Asner et al. [47] across four tropical regions in Panama, Peru, Madagascar, and Hawaii reported $\mathrm{R}^{2}$ ranging from 0.68 to 0.85 . Recently, a study from the tropical rainforest of Tanzania by Hansen et al. [9] reported $\mathrm{RMSE}_{\mathrm{CV}} \%$ ranging from
32.3 to $36.8 \%$ for models with different forms and different sets of predictor variables. However, direct comparison with these results should be taken with caution due to the wide range of variations existing in the tropical forests, along with the different sample sizes and plot sizes used in different studies.

Even though we are convinced that our findings reflect the potential performance of ALS-based AGB models in dry tropical forest conditions, but there might be ways to further improve the quality of the models. For instance, the plot size used in our study was relatively small compared to what has been used in the studies that reported higher prediction accuracy [e.g. 47, 52]. Most of these studies used plot sizes that are even twice as large as used in the current study. For example, Mauya et al. [53] reported a decrease in $\mathrm{RMSE}_{\mathrm{CV}}$ \% from 63.6 to $29.2 \%$ for plot sizes ranging from 200 to $3000 \mathrm{~m}^{2}$ in a high-biomass rainforest. The increase in prediction accuracy for studies based on larger plots might be attributed to the so-called spatial averaging of the errors, because both the field observations and the ALS data capture more of the spatial variation and are closer to the average value [e.g. 9, 54]. Furthermore, the relative and negative influence of plot positioning error on the prediction accuracy is reduced for the larger plot sizes, because the overlap between the field and ALS-data becomes larger as plot size increases [55]. In addition, plot boundary effect which has potential to cause discrepancies between field and ALS-based measurements, is reported to be relatively smaller for the larger plots compared to the smaller plots [53].

The concentric design of the field plots used in the current study also introduced errors in the relationships between AGB estimated on the plots and the ALS data. With this design, small trees are measured only in the center of a field plot while the largest trees are measured across the entire plot. However, smaller trees are also found in the outer part of a plot, and these trees will be measured by the laser but not recorded in the field data. Measuring all trees across a plot would clearly improve model fit. However, this study focused on the already existing design and data established by NAFORMA, thus it was also important to demonstrate how the NAFORMA data would be used with ALS auxiliary information. Similarly, miombo woodlands are dominated by a lower herbaceous layer of the vegetation which was not accounted for in the field measurements but were captured by the ALS data. Although a threshold of $1.3 \mathrm{~m}$ was applied to the ALS data to define the "canopy" layer, it is likely that the ALS data contains height observations reflected from vegetation that are not recorded by the tree measurements. This has certainly introduced additional errors into the models and reduced their performance. Lastly, it should be mentioned that the errors 
associated with the allometric models used to compute AGB (which were ignored in this study) will tend to affect the accuracy of the ALS-based prediction models. A general model by Mugasha et al. [56] that combines all the tree species was used to compute AGB on the ground plots. Given the high number of tree species it is likely that the uncertainty of the field-based reference values is substantial. To what extent this error affects the prediction accuracy of the ALS-based models is still unknown in the miombo woodlands and should be the focus of future research.

\section{Conclusion}

To conclude, our study demonstrated that predicting AGB using ALS data can be reliably done in the miombo woodlands of Tanzania. Our results on the comparison of the prediction methods have shown that LMM is the most appropriate method for AGB prediction using ALS data, as indicated by $\mathrm{RMSE}_{\mathrm{CV}} \%$, but also by considering its strength of accounting for the complex sampling design of the NAFORMA program. The prediction accuracy of $k$-NN was relatively smaller compared to LMM, yet it can be used when there is a need for using non-parametric method. Post-stratification by vegetation types seemed to favor the prediction accuracy compared to land use types. However, the non-post-stratified model has relatively more advantages due to its versatility and practical limitations of using post-strata models. Thus, we suggest using LMM (i.e., Model 3) that combines all the post-strata for applications involving large-scale AGB estimation in the future. Lastly, our study identified important knowledge gaps and directions of future research, such as assessing the effects of field plot size and the use of on-plot protocols which is based on complete census of all the trees in a plot, rather than a sample according to tree size. Finally, a better understanding and quantification of the effects of allometric model errors on overall uncertainties of ALS-based models and AGB estimates is a fundamental topic for future studies.

\section{Methods}

\section{Study area}

The study area is located in Liwale district $\left(9^{\circ} 54^{\prime} \mathrm{S}\right.$, $37^{\circ} 38^{\prime} \mathrm{E}$ ) (Fig. 5a), Lindi region, Tanzania, and has a total size of $15,867 \mathrm{~km}^{2}$ (Fig. 5b). The mean annual temperature of Liwale district ranges between 20 and $30{ }^{\circ} \mathrm{C}$. Rainfall pattern is bi-modal with a dry season from June to October. A short rainy period usually starts in late November and lasts until January. There is dry spell in February followed by a longer wet season which lasts from March until May. The mean annual rainfall ranges from 600 to $1000 \mathrm{~mm}$ [57]. The study area contains typical miombo flora of high trees with shrubs and grasses on the forest floor. In general, the area is characterized by a high species diversity associated with typical miombo tree species such as Brachystegia sp., Julbernadia sp., and Pterocarpus angolensis.

\section{Sampling design}

The field plots used in this study were initially established by NAFORMA in 2011. The sampling design used by NAFORMA is double-sampling for stratification which was designed based on a simulation study described by Tomppo et al. [6]. The first-phase sample consists of clusters of plots on a $5 \times 5 \mathrm{~km}$ grid over mainland Tanzania. The first-phase clusters were stratified based on predicted growing stock, time consumption for cluster measurements and slope of the terrain [6]. All together, the first-phase clusters that contain 6-10 plots (Fig. 5c) per cluster were assigned to 18 pre-defined strata. The second-phase samples were systematically selected from the first phase sample, with different sampling intensities in each of the 18 strata following an optimal allocation procedure [58] and with cost functions tailored for each stratum. Greater sampling intensity was allocated to strata with large predicted growing stock, and smaller sampling intensity to strata with small predicted growing stock. Only the clusters selected during the second phase of sampling were measured in the field. The distance between field plots within a cluster was $250 \mathrm{~m}$, while the distance between clusters varied from the shortest possible distance $(5 \mathrm{~km})$ to $45 \mathrm{~km}$.

\section{Field measurements}

NAFORMA field plots were revisited during the first quarter of 2012. The aim of the field work was to accurately record the positions of the field plots and update the field information to have temporal consistence between field measurements and the time of acquiring ALS data. Measurements on the plots followed the same procedure used by NAFORMA in 2011. The circular plots of $15 \mathrm{~m}$ radius were identified. Diameter at breast height $(d b h)$ was measured using caliper or diameter tape, following the lower $d b h$ thresholds in accordance with the concentric circle plot design. The radii of the concentric circles were $2,5,10$, and $15 \mathrm{~m}$, respectively. Trees with $d b h \geq 1, \geq 5, \geq 10$, and $\geq 20 \mathrm{~cm}$, respectively, were measured and assigned to these concentric plots.

Species names were recorded for every tree measured for $d b h$. Every fifth tree in the cluster was selected as a sample tree and measured for height using Suunto hypsometer. The heights of the remaining trees were predicted using diameter-height models that were developed based on the sample trees. Differential Global Navigation Satellite Systems were used to calculate the coordinates of the center point of each sample plot. Two Topcon Legacy 




40-channels dual frequency receivers observing both pseudo-range and carrier phase of the Global Positioning System (GPS), along with the Global Navigation Satellite System (GLONASS) were used as rover (on the plot) and base station, respectively. Based on the positional standard errors reported by Pinnacle [59], the estimated accuracy of the planimetric plot coordinates ranged from 0.004 to $1.334 \mathrm{~m}$, with an average of $0.194 \mathrm{~m}$.

Tree AGB was estimated using allometric models for miombo woodlands developed by Mugasha et al. [56] The AGB estimates of the individual trees were then summed for each plot, and scaled to per-hectare values according to their respective plot area determined by $d b h$-thresholds. The plots were grouped according to their respective stratum, land use, and vegetation types following the procedure described by NAFORMA in MNRT [60]. In this study, we narrowed the land use classes and the vegetation types described in MNRT [60] into three categories to simplify the interpretation of the results, but also to have enough samples for each category (Table 5). The land use classes were grouped into: (1) production and protection forests; (2) wildlife reserves; (3) agricultural and other land use types. Similarly, the vegetation types were grouped into: (1) forest; (2) woodlands; (3) other cover types.

\section{ALS data}

Acquisition of the ALS data was carried out along 32 parallel strips with an average width of $1374 \mathrm{~m}$, which were systematically distributed over the study area in an eastwest direction. The ALS strips were spaced $5 \mathrm{~km}$ apart, following the NAFORMA $5 \times 5 \mathrm{~km}$ grid. A Leica ALS 70 airborne laser sensor (Leica Geosystems AG, Switzerland), carried by a Cessna 404 aircraft, was used to acquire the data from 10 February to 7 March 2012. The measurements were acquired from an average flying altitude of approximately $1320 \mathrm{~m}$ above ground, at an average ground speed of $77.2 \mathrm{~ms}^{-1}$. The scanning rate was $36.5 \mathrm{~Hz}$ and the instrument operated at a pulse repetition frequency of $193 \mathrm{kHz}$. The average point density was around 1.8 points $\mathrm{m}^{-2}$.

Processing of the ALS data started by classifying the ALS echoes into ground or vegetation echoes using the progressive irregular triangular network densification method $[61,62]$ implemented in the TerraScan software [62]. A triangular irregular network (TIN) was created 
Table 5 Summary of field data

\begin{tabular}{|c|c|c|c|c|c|}
\hline \multirow[t]{2}{*}{ Category ${ }^{a}$} & \multirow[t]{2}{*}{ Number of plots } & \multicolumn{4}{|c|}{$\mathrm{AGB}\left(\mathrm{Mg} \mathrm{ha}^{-1}\right)$} \\
\hline & & Minimum & Maximum & Mean & Standard deviation \\
\hline \multicolumn{6}{|l|}{ Stratification } \\
\hline Stratum 5 & 116 & 3.9 & 158.2 & 45.9 & 29.8 \\
\hline Stratum 6 & 81 & 2.2 & 179.2 & 51.3 & 41.7 \\
\hline Stratum 7 & 90 & 2.4 & 270.3 & 84.7 & 61.3 \\
\hline Stratum 8 & 119 & 0.3 & 349.9 & 79.4 & 53.7 \\
\hline Stratum 9 & 23 & 0.3 & 125.6 & 38.7 & 35.4 \\
\hline Stratum 10 & 6 & 0.3 & 56.1 & 16.0 & 20.5 \\
\hline Stratum 11 & 16 & 55.1 & 186.9 & 87.9 & 32.4 \\
\hline Stratum 12 & 38 & 34.3 & 182.7 & 85.2 & 35.6 \\
\hline \multicolumn{6}{|l|}{ Post-stratification } \\
\hline \multicolumn{6}{|l|}{ Vegetation type } \\
\hline Forest & 40 & 27.8 & 232.2 & 88.3 & 39.6 \\
\hline Woodlands & 391 & 0.3 & 349.9 & 66.3 & 48.4 \\
\hline Other cover types & 58 & 0.3 & 270.3 & 46.9 & 53.7 \\
\hline \multicolumn{6}{|l|}{ Land use type } \\
\hline Production and protection forests & 314 & 0.3 & 349.9 & 75.6 & 49.5 \\
\hline Wildlife reserves & 91 & 0.3 & 190.6 & 50.8 & 39.0 \\
\hline Agriculture and other land uses & 84 & & 270.3 & 45.5 & 48.1 \\
\hline All & 489 & 0.3 & 349.9 & 65.8 & 49.2 \\
\hline
\end{tabular}

Number of plots for the different strata and post-strata together with minimum, maximum, and mean ground reference AGB values with their corresponding standard deviation

a Stratum 1-6 refers to the strata to which field plots belongs as described in the text and elaborated by Tomppo et al. [6]; Forest = land spanning more than 0.5 ha with trees that have heights of more than $5 \mathrm{~m}$ and a canopy cover of more than $10 \%$. It does not include land that is predominantly under agricultural or urban land use. Woodland = forestland with less dense canopy cover compared to forest. Other cover types = all cover types that were neither forest nor woodlands. Production and protection forests $=$ forest areas designated for protection of water (i.e. catchment forests) and that designated for production of wood, respectively. Wildlife reserves $=$ forest areas designated for game reserves and game controlled areas. Agriculture and other land use types $=$ areas designated primarily for a function other than production, protection or game reserves. Details descriptions of these categories are given in MNRT [60]

using the ALS echoes classified as ground echoes. The heights above the ground surface were then calculated for all vegetation echoes by subtracting the TIN height at their respective $x y$-positions. Up to five echoes were registered per pulse, but we used only the three echo categories "single", "first of many", and "last of many". The "single" and "first of many" echoes were pooled into one dataset denoted as "first" echoes, and correspondingly, the "single" and "last of many" echoes were pooled into a dataset denoted as "last" echoes.

For each echo category, height distributions were first created as described by Næsset [63]. A height threshold of $1.3 \mathrm{~m}$ was applied in order to separate trees from falsely classified ground features and low vegetation. Subsequently, heights at ten percentiles (0th, 10th,...,90th) of these height distributions were computed to represent canopy height distribution and labeled PF0, PF10,..., PF90 (first echoes) and PL0, PL10,..., PL90 (last echoes), respectively. Furthermore, measures of the canopy density were also computed for first and last echoes. The range between the lowest ALS canopy height $(>1.3 \mathrm{~m})$ and the 90th percentile height was divided into 10 layers of equal height. Canopy densities were then computed as the proportion of echoes above each layer to total number of first echoes and labeled TF0 (>1.3 m), TF1,.., TF9. Density variables for the last echo distributions were calculated in the same way and labeled TL0, TL1,...,TL9. Furthermore, mean (MeanF and MeanL), maximum (MaxF and MaxL) and coefficient of variation (CVF and CVL) of the canopy height distributions were also computed for both first and last echoes.

\section{Statistical analyses \\ An overview}

Three statistical techniques were used to develop relationships between the ground reference AGB and the ALS metrics. These included OLS, LMMs, and $k$-NN technique.

1. Candidate explanatory variables from the ALS metrics were selected and three OLS model forms relating ground reference AGB and ALS metrics were fitted and tested. 
2. The best selected model form from step 1 was used to build LMM with random effect at the cluster level.

3. To account for spatial dependence within the clusters we introduced LMMs with different correlation structures and compared with the LMM fitted in step 2.

4. LMM with variance structure at the cluster level was also fitted. The model was compared with the LMM fitted in step 2 using likelihood ratio testing. The best selected model (i.e., from step 1 to 4) was further evaluated using a cross validation procedure.

5. Finally, the $k-\mathrm{NN}$ imputations were fitted and compared with the best model selected from the procedure described above using measures of reliability based on cross validation.

\section{Parametric methods}

\section{Model development (OLS)}

OLS are among the most common methods for modeling and predicting AGB in ALS-based forest inventory. As part of the model development procedure, we first applied an automated approach to select candidate predictor variables using the "regsubset" function from the leaps package [64] in the $\mathrm{R}$ statistical software [65]. The "regsubset" regression performs "all subsets" where all possible variable combinations are considered and ranked based on different scoring criteria (adjusted $\mathrm{R}^{2}$, Mallow's $C_{p}$ statistics, BIC, etc.) [66]. In this study we used Mallow's $C_{p}$ statistics [67], a combination of predictors that minimizes the Mallow $C_{p}$ over all possible subsets, was considered as the best subset for model development. The variable selection was repeated for log-transformed variables and square root transformed response variable. Thus, three types of OLS models were finally fitted and tested. Of all the three model forms, square root transformation (Eq. 1) was selected as the best based on our initial test results (not presented), i.e.,

$$
\begin{aligned}
\sqrt{y_{j}} & =\beta_{0}+\beta_{1} x_{j 1}+\cdots+\beta_{k} x_{j k}+\epsilon_{j} \\
j & =1 \ldots n \quad \epsilon_{j} \sim N\left(0, \sigma_{\epsilon}^{2}\right)
\end{aligned}
$$

where $y_{j}$ is the ground reference AGB of the $j$ th sample plot, $x_{j 1} \ldots, x_{j k}$ are the $k$ predictor variables (i.e. ALS metrics), $\beta_{0}, \ldots, \beta_{k}$ are the parameter estimates, $n$ is the number of sample plots and $\varepsilon_{j}$ is the plot level residuals.

\section{Model development (LMM)}

The sampling design employed by NAFORMA imposes a hierarchical data structure by which the field plots are nested within the clusters. In such a case, LMM is considered as an ideal tool for development of predictive models $[22,68]$ that accounts for spatial dependence of the plots within the clusters. LMM consists of two main parts; fixed and random effects. The fixed effects are common to all subjects, while random effect parameters are specific to each subject [69]. The predictor variables of the OLS model (Eq. 1) were used as the fixed effects and the cluster number, or identity was used as the grouping variable (random effect), which can also be regarded as subject. The standard form of LMM as applied in this study is:

$$
\begin{aligned}
\sqrt{y_{i j}} & =\beta_{0}+\beta_{1} x_{i j}+\cdots+\beta_{k} x_{i j k}+b_{i}+\epsilon_{i j} \\
i & =1, \ldots, M \quad j=1, \ldots, n_{i} \\
b_{i} & \sim N\left(0, \sigma_{b}^{2}\right) \epsilon_{i j} \sim N\left(0, \sigma_{\epsilon}^{2}\right)
\end{aligned}
$$

where $y_{i j}$ is the ground reference AGB of $j$ th sample plot in the $i$ th cluster, $x_{i j 1}, \ldots, x_{i j k}$ are $k$ fixed effects, $\beta_{0}, \ldots, \beta_{k}$ are the fixed effects parameters, $n_{i}$ is the number of sample plots within the cluster $\mathrm{j}$ and $M$ is the number of clusters. We assumed that cluster level random effects $b_{i}$ were independent of the plot level residuals $\varepsilon_{i j}$.

To evaluate the significance of the random effect we refitted the OLS model using generalized least square function, in order to compare the OLS with the LMM using the likelihood ratio tests, as described by Zuur et al. [68].

To account for the non-constant variance and spatial autocorrelation that might not have been accounted for by the random effect, we further refitted the LMM with variance and correlation structures and compared with the LMM (i.e., the random intercept model). The details for this procedure are described below and elaborated further by Zuur et al. [68].

\section{LMMs with correlation structures}

We fitted five different LMMs using maximum likelihood estimation (ML), each assuming different spatial autocorrelation structures (i.e., linear, ratio, exponential, spherical, and Gaussian). This was aimed at testing the effect of spatial autocorrelation to account for field plot proximity within the clusters. In addition, we also tested compound symmetry correlation structure, assuming that correlation among plots within a cluster is constant but might vary from one cluster to another. The LMMs that incorporate spatial autocorrelation and compound symmetry correlation structures were compared with LMM without correlation structure (i.e., the random intercept model) using a likelihood ratio test. Details of these correlation structures are fully described in Pinheiro, Bates [69].

\section{LMM with variance structure}

To account for variation (i.e., heteroscedasticity due to cluster) not accounted for by the random effects, we also re-fitted the LMM (i.e., the random intercept model) 
assuming that the residuals were independent on cluster level. In this case, we used the varIdent variance function implemented in the nlme package [69]. The model was fitted using ML, and compared with LMM (i.e., the random intercept model) using the likelihood ratio test to determine the effect of cluster information on the model accuracy. Finally, the best model as indicated by the likelihood ratio test was refitted using restricted maximum likelihood (REML). To ensure that our modelling strategy has accounted for heteroscedasticity due to cluster structure, the residuals from the best model were further analyzed by fitting a residual intercept model (i.e., null model) and a residual random intercept model. The two models were compared using a likelihood ratio test to determine if we still have an effect of cluster structure in the residuals. Pseudo R-square $\left(R^{2}\right)$ computed as the square of the Pearson correlation coefficient between observed and predicted values was used to assess the quality of the model fit.

\section{Accuracy assessment}

To enable a fair comparison of the best LMM and nonparametric imputations (presented below), the prediction error of the best LMM was estimated by using leave-onecluster-out cross validation (LOCOCV) [70]. Owing to the number of clusters used in the current study and the lack of an independent validation dataset, LOCOCV was therefore applied. The predicted values of AGB obtained from the LOCOCV (i.e., $S \widehat{Q R T}(A G B)$ ) were corrected for bias (caused by the square root transformation) using the method by Gregoire et al. [71] according to

$$
\widehat{A G B}_{\text {corrected }}=(S \widehat{Q R} T(A G B))^{2}+M S E
$$

where $M S E$ is the mean square error of the model. Relative root mean square error from the LOCOCV $\left(R M S E_{C V} \%\right)$ was used as a criterion for assessing model accuracy and calculated as

$$
\operatorname{RMSE}_{C V} \%=\frac{\sqrt{\sum_{i=1}^{n}\left(y_{i}-\widehat{y}_{i}\right)^{2} / n}}{\bar{y}} \times 100
$$

where $y_{i}$ and $\hat{y}_{i}$ denote ground reference AGB and predicted AGB for plot $i$, respectively, and $\bar{y}$ denotes mean ground reference $\mathrm{AGB}$ for all plots. $\mathrm{RMSE}_{\mathrm{CV}} \%$ is a good measure of how accurately the model predicts the response and is the most important criterion for fit if the main purpose of the model is prediction [72].

\section{Non-parametric method k-NN imputation}

Imputation using $k-\mathrm{NN}$ is a non-parametric method that has often been used for predicting various attributes in forest inventories supported by remotely sensed auxiliary information [e.g. 73, 74]. In $k$-NN terminology it is typically distinguished between reference and target datasets. The population units for which observations of both response and explanatory variables are available is labeled as the reference set; the set of the population units for which only the explanatory variables are available is termed as the target set. In our study, the reference set contained both ground reference AGB and the ALS metrics, while the target set contained only the ALS metrics.

The similarity between the $i$ th target observation and $j$ th reference observation was quantified by means of the Euclidian distances calculated in the feature space as:

$$
d_{i j}=\sqrt{\left(x_{i}-x_{j}\right)^{\prime}\left(x_{i}-x_{j}\right)}
$$

where $x_{i}$ and $x_{j}$ are the feature vectors. Hence, the similarity between the target and reference observations will increase as the $d_{i j}$ distances decrease, and consequently the nearest neighbor of the $i$ th target observation is the reference observation located at the shortest Euclidian distance in the feature space.

The imputed value $\hat{y}_{i}$ is expressed as a weighted sum of the responses taken from the nearest $k$ reference observations as follows:

$$
\widehat{y}_{i}=\sum_{j=1}^{k} w_{i j} y_{j}^{i}
$$

where $y_{i j}^{i} j=1,2, \ldots k$ is the set of the response variable observations for the $k$ reference set elements that are nearest to the ith target set elements in the feature space. The $k$-weights associated with the response in Eq. 6 were obtained as

$$
w_{i j}=d_{i j}\left[\sum_{j=1}^{k} d_{i j}\right]^{-1}
$$

In order to reduce the data redundancy and improve the overall interpretability, a variable selection procedure was applied by using varSelection function in yaImpute package [75] of the $\mathrm{R}$ software [65]. Model fitting was done by using knnreg function in caret package [76]. For $k$-NN imputations, selection of $k$ has an influence on the accuracy of the imputation. Large values of $k$ are not recommended since this will shift the predictions towards the sample mean. For this study we tested the values of $k$ ranging from 1 to 10 and selected the value with lowest RMSE $_{C V} \%$ obtained from the cross validation. Specifically, we used LOCOCV, where one cluster at time was used as the target set while the remaining clusters were used at the reference set. To assess the ability of the $k$ $\mathrm{NN}$ to account for the dependence and heteroscedasticity 
due to cluster structure, we computed the residuals from the LOCOCV, then we fitted a residual intercept model and compared with residual random intercept model using likelihood ratio test. Lastly, we compared $k$-NN and LMM using RMSE $_{\mathrm{CV}} \%$.

\section{Assessing the effect of post-stratification on prediction accuracy}

To account for the variation in prediction accuracy that might be attributed to the differences in vegetation and land use types, the best LMM (i.e., LMM with variance structure) was further evaluated for different vegetation and land use types. Both relative root mean square errors from model predictions (RMSE \%) and LOCOCV $\left(\mathrm{RMSE}_{\mathrm{CV}} \%\right)$ were calculated and presented for each category of vegetation and land use type. Specific LMMs (i.e., random intercept models) were fitted for the poststrata as defined by vegetation and land use types. The models were evaluated using LOCOCV. For each of the post-stratum model, $\mathrm{R}^{2}$ and $\mathrm{RMSE}_{\mathrm{CV}} \%$ were computed and compared with the RMSE ${ }_{C V} \%$ obtained when evaluating the non-post-stratified model for the respective post-stratum.

\begin{abstract}
Abbreviations
ABA: area-based approach; AGB: aboveground biomass; AIC: akaike information criterion; ALS: airborne laser scanning; GLONASS: global navigation satellite system; GPS: global positioning system; $k$-NN: $k$-nearest neighbors; LMM: linear mixed effects model; LMMs: linear mixed effects models; LOCOCV: leave-one-cluster-out cross validation; MRV: measuring, reporting and verification; MSE: mean square error; OLS: ordinary least square; REDD+: reducing emissions from deforestation and forest degradation; RMSE: root mean square

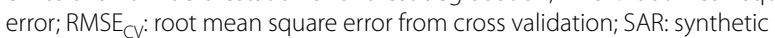
aperture radar; SE: standard error; SSE: sum of square error; TIN: triangular irregular network; UNFCCC: United Nations Framework Convention on Climate Change.
\end{abstract}

\section{Authors' contributions}

EWM and LTE were involved in designing the study, drafting the manuscript, data analysis and write up. OMB was involved in data analysis and revising the manuscript. EN and TG were responsible for designing the ALS acquisition and they were involved in revising the manuscript. REM and EZ were involved in planning the field inventory and revising the manuscript. All authors read and approved the final manuscript.

\section{Authors' information}

EWM is a PhD student in forest inventory at Norwegian University of Life Sciences (NBMU). He is associated with the forest mensuration group in Department of Ecology and Natural Resources Management at NMBU. ETH and $\mathrm{OMB}$ are researchers in the same group specializing in the application of ALS in forestry. EN and TG are senior scientists and professors in forest inventory and forest management at NMBU. Both EN and TG are resource persons for the forest mensuration group at NMBU. REM is professor in forest inventory at Sokoine University of Agriculture (SUA), Tanzania, while EZ is senior lecturer in forest inventory and MRV expert at SUA.

\section{Author details}

1 Department of Ecology and Natural Resource Management, Norwegian University of Life Sciences, P.O. Box 5003, 1432 Ås, Norway. ${ }^{2}$ Department of Forest Mensuration and Management, Sokoine University of Agriculture, P.O. Box 3013, Morogoro, Tanzania.

\section{Acknowledgements}

The financial support for this research was provided by the projects entitled "Enhancing the Measuring, Reporting and Verification (MRV) of forests in Tanzania through the application of advanced remote sensing techniques". The main author also acknowledges the project entitled "Climate Change Impacts, Adaptation and Mitigation (CCIAM) in Tanzania" for financing his study which resulted in this publication. We are grateful to our field team in Tanzania for the field data collection and Terratec, Norway, for collecting and processing the ALS data. We would also like to acknowledge the administration of Liwale district council for all support, and especially for providing us with office space.

\section{Competing interests}

The authors declare that they have no competing interests.

Received: 20 July 2015 Accepted: 12 October 2015

Published online: 02 December 2015

\section{References}

1. Martin AR, Thomas SC. A reassessment of carbon content in tropical trees. PLoS One. 2011;6:e23533.

2. Herold M, Skutsch M. Monitoring, reporting and verification for national REDD plus programmes: two proposals. Environ Res Lett. 2011. doi:10.1088/1748-9326/6/1/014002.

3. Joseph S, Herold M, Sunderlin WD, Verchot LV. REDD+ readiness: early insights on monitoring, reporting and verification systems of project developers. Environ Res Lett. 2013;8:034038.

4. MNRT. National forest resources monitoring and assessment of Tanzania mainland (NAFORMA). Main results. 2015. http://www.fao.org/forestry/43 612cf2f02c20b55c1c00569e679197dcde.pdf. Accessed 17 Aug 2015.

5. Burgess ND, Bahane B, Clairs T, Danielsen F, Dalsgaard S, Funder M, et al. Getting ready for REDD+ in Tanzania: a case study of progress and challenges. Oryx. 2010;44:339-51.

6. Tomppo E, Malimbwi R, Katila M, Mäkisara K, Henttonen H, Chamuya N, et al. A sampling design for a large area forest inventory-case Tanzania. Can J For Res. 2014;44:931-48.

7. Vauhkonen J, Maltamo M, McRoberts RE, Næsset E. Introduction to forestry applications of airborne laser scanning. In: Maltamo M, Næsset E, Vauhkonen J, editors. Forestry applications of airborne laser scanning concepts and case studies. Dordrecht: Springer; 2014. p. 1-16.

8. Næsset E. Area-based inventory in Norway-from innovation to an operational reality. In: Maltamo M, Næsset E, Vauhkonen J, editors. Forestry applications of airborne laser scanning — concepts and case studies. Dordrecht: Springer; 2014. p. 215-40.

9. Hansen EH, Gobakken T, Bollandsås OM, Zahabu E, Næsset E. Modeling aboveground biomass in dense tropical submontane rainforest using airborne laser scanner data. Remote Sens. 2015;7:788-807.

10. Ioki K, Tsuyuki S, Hirata Y, Phua M-H, Wong WVC, Ling Z-Y, et al. Estimating above-ground biomass of tropical rainforest of different degradation levels in Northern Borneo using airborne LiDAR. For Ecol Manage. 2014;328:335-41. doi:10.1016/j.foreco.2014.06.003.

11. Wulder MA, White JC, Nelson RF, Næsset E, Ørka HO, Coops NC, et al. Lidar sampling for large-area forest characterization: a review. Remote Sens Environ. 2012;121:196-209. doi:10.1016/j.rse.2012.02.001.

12. Gobakken T, Næsset E, Nelson R, Bollandsås OM, Gregoire TG, Ståhl G, et al. Estimating biomass in Hedmark County, Norway using national forest inventory field plots and airborne laser scanning. Remote Sens Environ. 2012;123:443-56. doi:10.1016/j.rse.2012.01.025.

13. Gregoire TG, Ståhl G, Næsset E, Gobakken T, Nelson R, Holm S. Modelassisted estimation of biomass in a LiDAR sample survey in Hedmark County, Norway. This article is one of a selection of papers from extending forest inventory and monitoring over space and time. Can J For Res. 2010;41:83-95.

14. McRoberts RE, Andersen $\mathrm{H}-\mathrm{E}$, Næsset E. Using airborne laser scanning data to support forest sample surveys. Forestry applications of airborne laser scanning. In: Maltamo M, Næsset E, Vauhkonen J, editors. Forestry applications of airborne laser scanning — concepts and case studies. Dordrecht: Springer; 2014. p. 269-92. 
15. Fassnacht FE, Hartig F, Latifi H, Berger C, Hernández J, Corvalán P, et al. Importance of sample size, data type and prediction method for remote sensing-based estimations of aboveground forest biomass. Remote Sens Environ. 2014;154:102-14. doi:10.1016/j.rse.2014.07.028.

16. Garcia-Gutierrez J, Gonzalez-Ferreiro E, Riquelme-Santos JC, Miranda D, Dieguez-Aranda U, Navarro-Cerrillo RM. Evolutionary feature selection to estimate forest stand variables using LiDAR. Int J Appl Earth Obs Geoinf. 2014;26:119-31. doi:10.1016/j.jag.2013.06.005.

17. Garcıa-Gutiérreza J, Martınez-Álvarezb F, Troncosob A, Riquelmea J. A comparison of machine learning regression techniques for LiDAR-derived estimation of forest variables. Neurocomputing. 2015

18. Montgomery DC, Peck EA, Vining GG. Introduction to linear regression analysis. New York: Wiley; 2012

19. García S, Fernández A, Luengo J, Herrera F. Advanced nonparametric tests for multiple comparisons in the design of experiments in computational intelligence and data mining: experimental analysis of power. Inf Sci. 2010;180:2044-64. doi:10.1016/j.ins.2009.12.010.

20. Fox JC, Ades PK, Bi H. Stochastic structure and individual-tree growth models. For Ecol Manage. 2001;154:261-76. doi:10.1016/ S0378-112700632-0.

21. Tang M, Slud EV, Pfeiffer RM. Goodness of fit tests for linear mixed models. J Multivar Anal. 2014;130:176-93. doi:10.1016/j.jmva.2014.03.012.

22. Gałecki A, Burzykowski T. Linear mixed-effects models using R: a step-bystep approach. New York: Springer; 2013

23. Salas C, Ene L, Gregoire TG, Næsset E, Gobakken T. Modelling tree diameter from airborne laser scanning derived variables: a comparison of spatial statistical models. Remote Sens Environ. 2010;114:1277-85. doi:10.1016/j.rse.2010.01.020.

24. Packalén P, Maltamo M. The k-MSN method for the prediction of species-specific stand attributes using airborne laser scanning and aerial photographs. Remote Sens Environ. 2007;109:328-41. doi:10.1016/j.rse.2007.01.005.

25. Eskelson BN, Temesgen H, Lemay V, Barrett TM, Crookston NL, Hudak AT. The roles of nearest neighbor methods in imputing missing data in forest inventory and monitoring databases. Scand J For Res. 2009;24:235-46.

26. Ene LT, Næsset E, Gobakken T, Gregoire TG, Ståhl G, Holm S. A simulation approach for accuracy assessment of two-phase post-stratified estimation in large-area LiDAR biomass surveys. Remote Sens Environ. 2013;133:210-24. doi:10.1016/j.rse.2013.02.002

27. McRoberts RE, Tomppo EO, Finley AO, Heikkinen J. Estimating areal means and variances of forest attributes using the k-nearest neighbors technique and satellite imagery. Remote Sens Environ. 2007;111:466-80.

28. Beaudoin A, Bernier P, Guindon L, Villemaire P, Guo X, Stinson G, et al. Mapping attributes of Canada's forests at moderate resolution through $k$ NN and MODIS imagery. Can J For Res. 2014;44:521-32.

29. Chirici G, Corona P, Marchetti M, Mastronardi A, Maselli F, Bottai L et al. k-NN FOREST: a software for the non-parametric prediction and mapping of environmental variables by the k-nearest neighbors algorithm. Remote Sens Environ 2012:45:433-42.

30. Penner M, Pitt D, Woods M. Parametric vs. nonparametric LiDAR models for operational forest inventory in boreal Ontario. Can J Remote Sens. 2013;39:426-43.

31. Gagliasso D, Hummel S, Temesgen H. A comparison of selected parametric and non-parametric imputation methods for estimating forest biomass and basal area. Open J For. 2014;4:42.

32. Bollandsås OM, Maltamo M, Gobakken T, Næsset E. Comparing parametric and non-parametric modelling of diameter distributions on independent data using airborne laser scanning in a boreal conifer forest. Forestry. 2013;86:493-501.

33. Leitold V, Keller M, Morton DC, Cook BD, Shimabukuro YE. Airborne lidarbased estimates of tropical forest structure in complex terrain: opportunities and trade-offs for REDD+. Carbon Balance Manage. 2015;10:3.

34. Latifi H, Fassnacht FE, Hartig F, Berger C, Hernández J, Corvalán P, et al. Stratified aboveground forest biomass estimation by remote sensing data. Int J Appl Earth Obs Geoinf. 2015:38:229-41. doi:10.1016/j. jag.2015.01.016

35. Næsset E, Gobakken T. Estimation of above- and below-ground biomass across regions of the boreal forest zone using airborne laser. Remote Sens Environ. 2008;112:3079-90. doi:10.1016/j.rse.2008.03.004.

36. Næsset E. Predicting forest stand characteristics with airborne scanning laser using a practical two-stage procedure and field data. Remote Sens Environ. 2002;80:88-99. doi:10.1016/S0034-4257(01)00290-5.
37. Huang W, Sun G, Dubayah R, Cook B, Montesano P, Ni W, et al. Mapping biomass change after forest disturbance: applying LiDAR footprintderived models at key map scales. Remote Sens Environ. 2013;134:31932. doi:10.1016/j.rse.2013.03.017.

38. Chen Q, Vaglio Laurin G, Battles JJ, Saah D. Integration of airborne lidar and vegetation types derived from aerial photography for mapping aboveground live biomass. Remote Sens Environ. 2012;121:108-17. doi:10.1016/j.rse.2012.01.021.

39. Dewees PA, Campbell BM, Katerere Y, Sitoe A, Cunningham AB, Angelsen $A$, et al. Managing the Miombo woodlands of southern Africa: policies, incentives and options for the rural poor. J Nat Resour Policy Res. 2010;2:57-73.

40. Ribeiro NS, Matos CN, Moura IR, Washington-Allen RA, Ribeiro Al. Monitoring vegetation dynamics and carbon stock density in miombo woodlands. Carbon Balance Manage. 2013;8:1-9.

41. Haara A, Kangas A. Comparing K nearest neighbours methods and linear regression-is there reason to select one over the other? Math Comput For Nat Resour Sci (MCFNS). 2012;4:50-65.

42. Fehrmann L, Lehtonen A, Kleinn C, Tomppo E. Comparison of linear and mixed-effect regression models and ak-nearest neighbour approach for estimation of single-tree biomass. Can J For Res. 2008;38:1-9.

43. Baffetta F, Corona P, Fattorini L. Design-based diagnostics for k-NN estimators of forest resources. This article is one of a selection of papers from extending forest inventory and monitoring over space and time. Can J For Res. 2010;41:59-72.

44. Baffetta F, Fattorini L, Franceschi S, Corona P. Design-based approach to k-nearest neighbours technique for coupling field and remotely sensed data in forest surveys. Remote Sens Environ. 2009;113:463-75.

45. Ståhl G, Holm S, Gregoire TG, Gobakken T, Næsset E, Nelson R. Modelbased inference for biomass estimation in a LiDAR sample survey in Hedmark County, Norway. This article is one of a selection of papers from extending forest inventory and monitoring over space and time. Can $J$ For Res. 2010:41:96-107.

46. Mascaro J, Asner GP, Dent DH, DeWalt SJ, Denslow JS. Scale-dependence of aboveground carbon accumulation in secondary forests of Panama: a test of the intermediate peak hypothesis. For Ecol Manage. 2012;276:62-70.

47. Asner GP, Mascaro J, Muller-Landau HC, Vieilledent G, Vaudry R, Rasamoelina $M$, et al. A universal airborne LiDAR approach for tropical forest carbon mapping. Oecologia. 2012;168:1147-60.

48. Asner GP. Tropical forest carbon assessment: integrating satellite and airborne mapping approaches. Environ Res Lett. 2009;4:034009.

49. Asner GP, Powell GV, Mascaro J, Knapp DE, Clark JK, Jacobson J, et al. High-resolution forest carbon stocks and emissions in the Amazon. Proc Natl Acad Sci. 2010;107:16738-42.

50. Vaglio Laurin G, Chen Q, Lindsell JA, Coomes DA, Frate FD, Guerriero $L$, et al. Above ground biomass estimation in an African tropical forest with lidar and hyperspectral data. ISPRS J Photogramm Remote Sens. 2014;89:49-58. doi:10.1016/j.isprsjprs.2014.01.001.

51. Clark ML, Roberts DA, Ewel JJ, Clark DB. Estimation of tropical rain forest aboveground biomass with small-footprint lidar and hyperspectral sensors. Remote Sens Environ. 2011;115:2931-42. doi:10.1016/j. rse.2010.08.029

52. Mascaro J, Detto M, Asner GP, Muller-Landau HC. Evaluating uncertainty in mapping forest carbon with airborne LiDAR. Remote Sens Environ. 2011;115:3770-4.

53. Mauya E, Hansen E, Gobakken T, Bollandsås O, Malimbwi R, Næsset E. Effects of field plot size on prediction accuracy of aboveground biomass in airborne laser scanning-assisted inventories in tropical rain forests of Tanzania. Carbon Balance Manage. 2015;10:1-14. doi:10.1186/ s13021-015-0021-x.

54. Zolkos S, Goetz S, Dubayah R. A meta-analysis of terrestrial aboveground biomass estimation using lidar remote sensing. Remote Sens Environ. 2013;128:289-98.

55. Frazer GW, Magnussen S, Wulder MA, Niemann KO. Simulated impact of sample plot size and co-registration error on the accuracy and uncertainty of LiDAR-derived estimates of forest stand biomass. Remote Sens Environ. 2011;115:636-49. doi:10.1016/j.rse.2010.10.008.

56. Mugasha WA, Eid T, Bollandsås OM, Malimbwi RE, Chamshama SAO, Zahabu E, et al. Allometric models for prediction of above- and belowground biomass of trees in the miombo woodlands of Tanzania. For Ecol Manage. 2013;310:87-101. doi:10.1016/j.foreco.2013.08.003. 
57. LDC. Social economic profile of Liwale District Council. p 32

58. Cochran WG. Sampling techniques, vol. 98. New York: Wiley; 1977. p. 259-61.

59. Anon. Pinnacle user's manual; Javad positioning systems. In: Jose S, editor. CA. 1999

60. MNRT. NAFORMA field manual_biophysical. 2011. http://www.fao.org/ forestry/23484-05b4a32815ecc769685b21 b03be44ea77.pdf. Accessed 23 Feb 2014.

61. Axelsson P. Processing of laser scanner data-algorithms and applications. ISPRS J Photogramm Remote Sens. 1999;54:138-47.

62. Axelsson P. DEM generation from laser scanner data using adaptive TIN models. Int Arch Photogramm Remote Sens. 2000;33:111-8.

63. Næsset E. Practical large-scale forest stand inventory using a small-footprint airborne scanning laser. Scand J For Res. 2004;19:164-79.

64. Lumley T. Leaps: regression subset selection. R package version 2.9. 2009. http://CRAN.R-project.org/package=leaps. Accessed 15 Jan 2015.

65. Team RC. R: a language and environment for statistical computing. Vienna, Austria: R Foundation for Statistical Computing; 2012. Open access available at: http://cranr-project.org. 2014.

66. Tsui OW, Coops NC, Wulder MA, Marshall PL, McCardle A. Using multifrequency radar and discrete-return LiDAR measurements to estimate above-ground biomass and biomass components in a coastal temperate forest. ISPRS J Photogramm Remote Sens. 2012;69:121-33.
67. Mallows CL. Some comments on C p. Technometrics. 1973;15:661-75.

68. Zuur A, leno EN, Walker N, Saveliev AA, Smith GM. Mixed effects models and extensions in ecology with R. Berlin: Springer; 2009.

69. Pinheiro JC, Bates DM. Mixed-effects models in S and S-PLUS. Berlin: Springer; 2000.

70. James G, Witten D, Hastie T, Tibshirani R. An introduction to statistical learning. Berlin: Springer; 2013.

71. Gregoire TG, Lin QF, Boudreau J, Nelson R. Regression estimation following the square-root transformation of the response. Forest Science. 2008;54:597-606.

72. Yoo S, Im J, Wagner JE. Variable selection for hedonic model using machine learning approaches: a case study in Onondaga County, NY. Landsc Urban Plan. 2012;107:293-306. doi:10.1016/j. landurbplan.2012.06.009.

73. McRoberts RE. Estimating forest attribute parameters for small areas using nearest neighbors techniques. For Ecol Manage. 2012;272:3-12.

74. McRoberts RE, Tomppo EO. Remote sensing support for national forest inventories. Remote Sens Environ. 2007;110:412-9.

75. Crookston NL, Finley AO. yaimpute: an r package for knn imputation. J Stat Softw. 2008;23:1-16.

76. Engelhardt A, Kuhn MM. Package 'caret'. 2009. http://caret.r-forge.r-project.org/. Accessed 7 Jan 2014

\section{Submit your manuscript to a SpringerOpen ${ }^{\odot}$ journal and benefit from:}

- Convenient online submission

- Rigorous peer review

- Immediate publication on acceptance

- Open access: articles freely available online

- High visibility within the field

- Retaining the copyright to your article

Submit your next manuscript at $\boldsymbol{s p r i n g e r o p e n . c o m ~}$ 